\title{
BMJ Open The association between mentoring and training outcomes in junior doctors in medicine: an observational study
}

\author{
John Ong, ${ }^{1}$ Carla Swift, ${ }^{2}$ Nicholas Magill, ${ }^{3}$ Sharon Ong, ${ }^{4}$ Anne Day, ${ }^{1}$ \\ Yasseen Al-Naeeb, ${ }^{1}$ Arun Shankar ${ }^{5}$
}

To cite: Ong J, Swift C, Magill $\mathrm{N}$, et al. The association between mentoring and training outcomes in junior doctors in medicine: an observational study. BMJ Open 2018;8:e020721. doi:10.1136/ bmjopen-2017-020721

- Prepublication history and additional material for this paper are available online. To view these files, please visit the journal online (http://dx.doi. org/10.1136/bmjopen-2017020721).

Received 22 November 2017

Revised 27 July 2018

Accepted 8 August 2018

Check for updates

(c) Author(s) (or their employer(s)) 2018. Re-use permitted under CC BY-NC. No commercial re-use. See rights and permissions. Published by BMJ.

\section{${ }^{1}$ Department of}

Gastroenterology, Bedford

Hospital, Bedford, UK

${ }^{2}$ Department of

Gastroenterology, Addenbrooke's Cambridge University Hospital, Cambridge, UK

${ }^{3}$ Department of Biostatistics and Health Informatics, King's

College London, London, UK

${ }^{4}$ Department of Anaesthesia, Singapore General Hospital,

Singapore

${ }^{5}$ Department of

Gastroenterology, Norfolk \&

Norwich University Hospital,

Norwich, UK

Correspondence to

Dr John Ong;

john.ong@kcl.ac.uk

\section{ABSTRACT}

Objective To determine quantitatively if a positive association exists between the mentoring of junior doctors and better training outcomes in postgraduate medical training within the UK.

Design Observational study.

Participants 117 trainees from the East of England Deanery (non-mentored group) and the recently established Royal College of Physicians (RCP) Mentoring scheme (mentored group) who were core medical trainees (CMTs) between 2015 and 2017 completed an online survey. Trainees who received mentoring at the start of higher specialty training, incomplete responses and trainees who were a part of both the East of England deanery and RCP Mentoring scheme were excluded leaving 85 trainees in the non-mentored arm and 25 trainees in the mentored arm. Responses from a total of 110 trainees were analysed.

Main outcome measures Pass rates of the various components of the Membership of the Royal College of Physicians (MRCP) (UK) examination (MRCP Part 1, MRCP Part 2 Written and MRCP Part 2 PACES), pass rates at the Annual Review of Competency Progression (ARCP), trainee involvement in significant events, clinical incidents or complaints and trainee feedback on career progression and confidence.

Results Mentored trainees reported higher pass rates of the MRCP Part 1 exam versus non-mentored trainees ( $84.0 \%$ vs $42.4 \%, p<0.01)$. Mentored international medical graduates (IMGs) reported higher pass rates than non-mentored IMGs in the MRCP Part 2 Written exam (71.4\% vs $24.0 \%, p<0.05)$. ARCP pass rates in mentored trainees were observed to be higher than non-mentored trainees $(95.8 \%$ vs $69.9 \%, p<0.05)$. Rates of involvement in significant events, clinical incidents and complaints in both groups did not show any statistical difference. Mentored trainees reported higher confidence and career progression.

Conclusions A positive association is observed between the mentoring of CMTs and better training outcomes. Further studies are needed to investigate the causative effects of mentoring in postgraduate medical training within the UK.

\section{INTRODUCTION}

Work-based mentoring is a growing and encouraged practice in UK postgraduate

\section{Strengths and limitations of this study}

- Novel quantitative data demonstrating a positive association between mentoring and better training-specific outcomes in core medical trainees.

- Adds to the limited qualitative data on the effects of mentoring in postgraduate medical training within the UK.

- Potential for non-response bias and self-selection bias.

- Small sample size of international medical graduates who received mentoring.

- Provides preliminary evidence to support further studies investigating the causative effects of mentoring in UK medical trainees.

medical training. ${ }^{1}$ Although qualitative data suggest that mentored trainees do generally have a positive experience, there is little quantitative evidence to suggest this directly and positively impacts on training-specific outcomes in postgraduate medicine. ${ }^{2}$ Here, we studied two groups of junior medical doctors in training and compared targeted training outcomes in a group of trainees who had received mentorship in a structured mentoring programme versus a non-mentored group. By default, mentoring is not provided to all trainees in the UK.

Mentoring is defined as 'a process whereby an experienced, highly regarded, empathic person (the mentor) guides another usually younger individual (the mentee) in the development and re-examination of their own ideas, learning and personal or professional development'. ${ }^{3}$ It describes a voluntary and synergistic relationship, which requires commitment from both parties in order to be effective. ${ }^{4}$ Its ultimate purpose is to empower an individual to achieve set goals, ${ }^{4}$ although these goals inevitably evolve over time as the mentee develops. ${ }^{3}$

In many studies in literature, failed mentormentee relationships are a result of poor 
communication, lack of commitment, personality differences, competition, conflicts of interest, mentor inexperience $^{5}$ and unrealistic mentee expectations. ${ }^{4}{ }^{6}$ To minimise these problems, we included trainees from the Royal College of Physicians (RCP) Mentoring scheme, an optional and recently established mentoring programme made available to any interested core medical trainee in the UK. The programme was advertised through RCP newsletters, social media or peer recommendations. Interested trainees accessed and applied to join the scheme online. Once accepted into the programme, mentees chose their mentors based on online mentor profiles to improve mentor-mentee compatibility. Mentors in the scheme comprise senior registrars and consultants from different medical specialties. They were recruited via RCP newsletters, screened then received formal, compulsory training in mentorship and effective communication over two days prior to accepting mentees. Mentoring was voluntary and no financial incentives were offered to the mentors.

At the start of the mentor-mentee relationship, mentors engaged in goal setting (eg, SMART objectives) to avoid unrealistic expectations by mentees. Subsequently, mentors employed effective questioning techniques to encourage mentee reflection, planning and decision making before dispensing advice or intervention depending on which approach was most appropriate (eg, facilitative or directive). Mentors were also provided with a platform to obtain confidential, third-party advice to ensure difficult situations are dealt with appropriately.

As easy accessibility and open communication are important factors for a successful mentor-mentee relationship, ${ }^{5}$ mentors and mentees in the RCP mentoring scheme were provided the option to conduct mentormentee meetings either in person, online or both. Mentees determined the mode, frequency and duration of the meetings. The most frequent method of communication was email but this was often combined with online conferencing and in-person meetings. Although some studies question the quality and validity of online mentoring, ${ }^{78}$ others have argued it can still be effective ${ }^{910}$ and provides opportunities for mentoring when it would otherwise not be possible. ${ }^{9}$ We have chosen not to investigate the mode of how mentoring was delivered in this study because it makes quantitative analysis difficult and does not answer the research question posed by this study.

The objective of our study is to determine quantitatively if a positive association exists between the mentoring of junior doctors and better training outcomes in postgraduate medical training within the UK.

\section{METHODS}

\section{Rationale of study design}

A questionnaire was designed to enable the quantitative analysis of training-specific outcomes and the qualitative analysis of trainee feedback. Parameters for quantitative analysis were the (i) pass rates of the Membership of the
Royal College of Physicians (MRCP) UK exams, (ii) pass rates of the Annual Review of Competence Progression (ARCP) and (iii) the rate of trainee involvement in significant events (SEs), clinical incidents (CIs) and complaints.

The MRCP (UK) exam is a postgraduate exam in general internal medicine, which comprises three parts: MRCP Part 1 Written, MRCP Part 2 Written and the MRCP Part 2 PACES (practical component). The MRCP (UK) diploma is awarded on completion of all three exams and completion of the MRCP Part 1 Written exam is required before a trainee can sit for the other two exams. Completion of the MRCP (UK) diploma is expected by the end of core medical training and is a prerequisite to joining a higher specialty training (ST) programme in medicine within the UK. Completion of these examinations is an objective indicator that a trainee has achieved the medical knowledge required for their stage of training.

In postgraduate medical training in the USA, the Accreditation Council for Graduate Medical Education (ACGME) assesses trainee progress in the six domains of patient care, medical knowledge, practice-based learning and improvement, interpersonal and communication skills, professionalism and system-based practice. Each domain has 'milestones', which trainees are expected to achieve at different stages of training. In the UK, a similar approach is adopted and progress is determined by the ARCP review. The ARCP review occurs annually and involves a panel of senior clinical educators and physicians assessing a trainee's progress in the domains of multiple consultant reports, educational supervisor report, advanced life support, supervised learning events, multisource feedback, research and audit, common procedural competencies, non-procedural competencies (eg, communication skills, history taking, etc), top medical presentations, emergency medical presentations, other medical presentations, clinics and teaching attendance. The trainee submits evidence to the panel to demonstrate the domain requirements have been achieved and an outcome is awarded to the trainee after the entire review process. Outcome 1, the equivalent of a pass, is described as 'satisfactory progress-achieving progress and competencies at expected rate'. Other outcomes relevant to core medical training are similar to a fail. The ARCP pass rate was chosen as a parameter of interest because it is an indirect but objective indicator of a trainee's all-rounded development in both the educational curriculum and clinical practice.

The National Patient Safety Agency (NPSA) in the UK defines an SE as 'any event (negative) thought by anyone in the team to be significant in the care of patients or conduct of practice'. ${ }^{11}$ The CI is often used to describe an unintentional or unexpected event that is less severe in nature and which does not cause significant harm to a patient or member of staff. As part of the ARCP process, it is mandatory for all trainees to declare any involvement in SEs, CIs or complaints received to the ARCP panel. In this study, we also investigated if mentoring or the lack 
thereof, had any association with trainee involvement in SEs, CIs or complaints.

Trainees from the RCP mentoring programme were chosen as the mentored group because of its nationwide recruitment, which reduces the risk of interdeanery variability if any. East of England (EoE) trainees were chosen as a control group because, at the time of the study, no mentoring programme for medicine was active within the region. In contrast, other regional deaneries had separate mentoring programmes for junior doctors (eg, London deanery, Health Education England Thames Valley deanery). This would have limited standardisation of mentored and non-mentored groups (eg, career grade of mentors, level of training delivered to mentors, mentees from other mentoring programmes responding to our survey, etc). To provide context to our results, we also provide the pass rates for all UK candidates in the 2017 MRCP exams. ${ }^{12}$

\section{Design and administration of questionnaire}

The questionnaire comprised 14 binary, non-Likert questions and 1 open question, which enabled free-text entry for the qualitative analysis of a trainee's experience of being mentored. The qualitative questions within the questionnaire also served as an internal check, so that quantitative results from the survey could be validated against trainee experience (eg, MRCP or ARCP Pass rates vs "Did mentoring help your career progression?"). The questionnaire was pretested on a small group of medical registrars not involved with the study to assess its ability at extracting the information required for the study. Minor revisions were made and a final Cronbach's alpha score of 0.83 was achieved. The final questionnaire was sent via email as a link to an online survey to all core medical trainees (CMTs) within the East of England Deanery between 2015 and 2017 ( $\mathrm{n}=540$ trainees, non-mentored group), and all CMTs who voluntarily registered with the RCP Mentoring scheme between 2015 and 2017 ( $\mathrm{n}=160$, mentored group). None of the authors participated in the survey. The survey was subsequently conducted from 14 August 2017 to 15 September 2017 to capture data from trainees at the start of their posts. One reminder email was sent 2 weeks after the invitation email.

\section{Ethics}

Prior to designing the survey, the authors completed the Medical Research Council and NHS Health Research Authority decision tool (www.hra-decisiontools.org.uk), which determined ethical approval from a local research ethics committee was not required. This decision is attached as online supplementary appendix 1 .

All participants were automatically anonymised by the online survey platform and trainees were made aware of this in their invitation email. Trainees were also informed the survey was for research purposes and participation was voluntary. Completion of the survey conferred implied consent and the authors only received anonymised responses with no trainee identifiable information.
There was no risk posed to participants and participants were not paid for completed questionnaires.

\section{Patient and public involvement}

This study did not involve any members of the public or patients.

\section{Exclusion criteria}

Of the 700 trainees that the invitations were sent to, responses from 117 trainees were received. Of the 117 responses, trainees who received mentoring at the start of higher ST; ST3 or above $(\mathrm{n}=2)$, incomplete responses $(n=3)$ and trainees who were both a part of the East of England deanery and the RCP Mentoring scheme $(n=2)$ were excluded. Incomplete responses were defined as surveys with $<50 \%$ of answered questions. The survey was conducted as a sequence of questions, one question at a time. The first half of the survey collected demographic data, therefore surveys with $<50 \%$ of answered questions were not interpretable. A total of seven returned surveys were excluded. All of the other 110 surveys were adequately completed.

Other grades of junior doctors equivalent to CMTs (eg, CMT grade clinical fellows and Locum Appointment for Training Senior House (LAT SHOs)) were classed 'others' but included in the analysis since these numbers were relatively small. The final numbers for comparison were 25 trainees in the mentored group and 85 trainees in the non-mentored group (summarised in figure 1).

\section{Statistical and qualitative analyses}

Graphpad V.7.0 (by PRISM) was used to perform the statistical analyses between the two groups of trainees. The $X^{2}$ test was used to examine whether mentoring was associated with outcomes, which were all binary, provided that frequencies within cells of a contingency table were all greater than five. Where this assumption of the $X^{2}$ was broken and there were fewer than five trainees in one or more cells of a contingency table, Fisher's exact test was used to calculate $\mathrm{p}$ values. The $\mathrm{X}^{2}$ test of association was performed for age, stage of training, qualification status and gender in mentored versus non-mentored groups. The significance level was set to $5 \%$ for all tests and all alternative hypotheses were two sided. The Koopman asymptotic method ${ }^{13}$ was used to calculate the CIs of the relative risk (RR) and the Baptista-Pike method was used to calculate CIs for the OR. ${ }^{14}$ Since our hypothesis tests were exploratory, we did not consider adjusting for multiple testing to be necessary. Our approach is supported by evidence that suggest making adjustments for multiple comparisons can lead to an increased number of errors of interpretation when data being evaluated are actual observations. ${ }^{15}$

MedCalc V.18 was used to perform logistic regression. Older age of respondents may have been a confounding factor to MRCP pass rates if respondents had more time out of training to complete the exams. Lower pass rates of international medical graduates (IMGs) are 


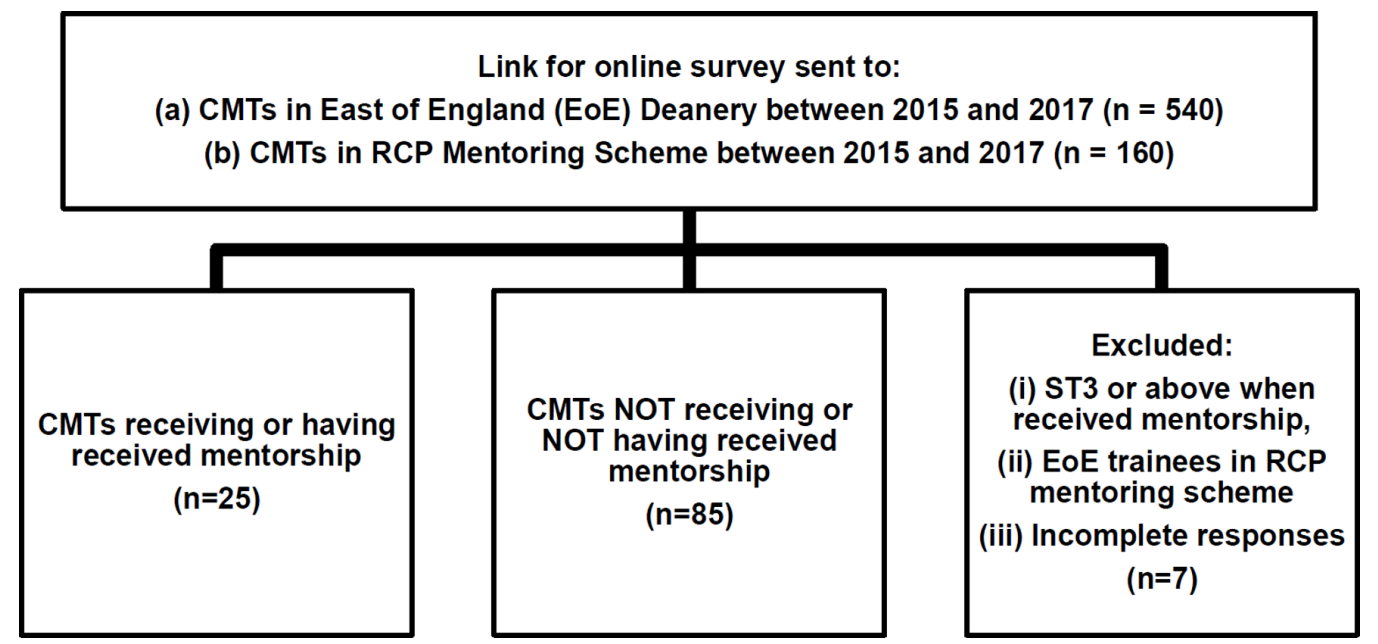

Figure 1 Distribution of responses received into 'mentored', 'not mentored' arms and responses excluded in the study. CMT, core medical trainee; RCP, Royal College of Physicians; ST, specialty training.

usually observed in the MRCP exams and the reason for this phenomenon is likely multifactorial. For both these reasons, age group (coded as $0=20-30$ years, $1=31-40$ years $)$ and the country of the primary medical degree (coded as $\mathrm{UK}=1$, non- $\mathrm{UK}=0$ ) of respondents were used as covariates in the regression model together with exposure to mentoring in order to make an assessment of any confounding of the relationship between mentoring and outcome. Since completion of MRCP exams is expected with career progression, stage of training was not used as a covariate in the regression model.

Qualitative responses were grouped into categories of 'positive' or 'negative' feedback when applicable and descriptors provided by the trainees were summarised. Examples of the feedback received have also been quoted verbatim in the 'Results' section for readers to interpret.

\section{RESULTS}

Of the 110 trainees in the study (85 non-mentored, 25 mentored), there were slightly more female respondents than male in both arms of the study; $56.0 \%(14 / 25)$ vs $44.0 \%(11 / 25)$ in the mentored group and $51.8 \%$ $(44 / 85)$ vs $48.2 \%(41 / 85)$ in the non-mentored group. There were no statistically significant differences in the career grades of the respondents in both arms of the study and the majority of respondents were graduates from the UK (table 1).

Significant differences were observed in the MRCP exam pass rates between mentored and non-mentored trainees

The pass rate of the MRCP Part 1 exam was observed to be significantly higher in trainees receiving mentorship compared with non-mentored East of England trainees; $84.0 \%(21 / 25)$ vs $42.4 \%(36 / 85), \mathrm{p}<0.01(\mathrm{OR}=7.1,95 \% \mathrm{CI}$ 2.4 to 20.3 and $\mathrm{RR}=2.0,95 \%$ CI 1.4 to 2.7 ) (table 2). This effect is also observed when trainees are grouped by their stage of training (online supplementary table 1).

Logistic regression demonstrated mentoring to be strongly associated with higher pass rates of the MRCP
Part 1 exam $(p<0.001)$ with a point estimate of effect size equating to adjusted $\mathrm{OR}=9.56,95 \%$ CI 2.56 to 35.68 (table 3).

The MRCP Part 2 (Written) exam pass rates between mentored trainees and non-mentored East of England trainees showed no significant difference. This was further reflected in the logistic regression model $(p=0.29$ and

Table 1 Demographics of respondents grouped by gender, current stage of training, country of primary medical qualification and age group

\begin{tabular}{|c|c|c|c|}
\hline & $\begin{array}{l}\text { Mentored } \\
\text { (1) }\end{array}$ & $\begin{array}{l}\text { Non-mentored } \\
\text { (2) }\end{array}$ & $\begin{array}{l}\text { P values } \\
\text { (1) vs (2) }\end{array}$ \\
\hline Gender & & & 0.71 \\
\hline Male & $\begin{array}{l}44.0 \% \\
(11 / 25)\end{array}$ & $48.2 \%(41 / 85)$ & \\
\hline Female & $\begin{array}{l}56.0 \% \\
(14 / 25)\end{array}$ & $51.8 \%(44 / 85)$ & \\
\hline Stage of training & & & 0.13 \\
\hline FY1 & $0.0 \%(0 / 25)$ & $0.0 \%(0 / 85)$ & \\
\hline FY2 & $0.0 \%(0 / 25)$ & $0.0 \%(0 / 85)$ & \\
\hline CMT1 & $16.0 \%(4 / 25)$ & $36.5 \%(31 / 85)$ & \\
\hline СMT2 & $32.0 \%(8 / 25)$ & $34.1 \%(29 / 85)$ & \\
\hline ST3 or above & $28.0 \%(7 / 25)$ & $17.6 \%(15 / 85)$ & \\
\hline Others & $24.0 \%(6 / 25)$ & $11.8 \%(10 / 85)$ & \\
\hline Primary degree & & & 0.89 \\
\hline UK trained & $\begin{array}{l}72.0 \% \\
(18 / 25)\end{array}$ & $70.6 \%(60 / 85)$ & \\
\hline IMG & $28.0 \%(7 / 25)$ & $29.4 \%(25 / 85)$ & \\
\hline Age group (years) & & & 0.96 \\
\hline $20-30$ & $\begin{array}{l}76.0 \% \\
(19 / 25)\end{array}$ & $76.5 \%(65 / 85)$ & \\
\hline $31-40$ & $24.0 \%(6 / 25)$ & $23.5 \%(20 / 85)$ & \\
\hline
\end{tabular}

CMT, core medical trainee; FY, foundation year; IMG, international medical graduate; ST, specialty training. 
Table 2 MRCP (UK) pass rates for all trainees and UK international medical graduates who participated in the study

\begin{tabular}{|c|c|c|c|c|c|c|c|}
\hline & Pass rate $\mathrm{i}$ & all trainees & & $\begin{array}{l}\text { Pass rate } \mathrm{i} \\
\text { internation }\end{array}$ & $\begin{array}{l}\text { UK } \\
\text { medical gradua }\end{array}$ & tes & \\
\hline & $\begin{array}{l}\text { Mentored } \\
\text { (1) }\end{array}$ & $\begin{array}{l}\text { Non- } \\
\text { mentored } \\
(2)\end{array}$ & $\begin{array}{l}P \text { values } \\
\text { (1) vs (2) }\end{array}$ & $\begin{array}{l}\text { Mentored } \\
\text { (3) }\end{array}$ & $\begin{array}{l}\text { Non-mentored } \\
\text { (4) }\end{array}$ & $\begin{array}{l}P \text { values } \\
\text { (3) vs (4) }\end{array}$ & $\begin{array}{l}2017 \text { UK } \\
\text { pass rates }\end{array}$ \\
\hline $\begin{array}{l}\text { MRCP Part } 1 \\
\text { (Written) }\end{array}$ & $\begin{array}{l}84.0 \% \\
(21 / 25)\end{array}$ & $\begin{array}{l}42.4 \% \\
(36 / 85)\end{array}$ & $<0.01$ & $\begin{array}{l}71.4 \% \\
(5 / 7)\end{array}$ & $\begin{array}{l}32.0 \% \\
(8 / 25)\end{array}$ & 0.09 & $\begin{array}{l}50.6 \% \\
(2065 / 4079)\end{array}$ \\
\hline $\begin{array}{l}\text { MRCP Part } 2 \\
\text { (PACES) }\end{array}$ & $\begin{array}{l}44.0 \% \\
(11 / 25)\end{array}$ & $\begin{array}{l}29.4 \% \\
(25 / 85)\end{array}$ & 0.17 & $\begin{array}{l}57.1 \% \\
(4 / 7)\end{array}$ & $\begin{array}{l}24.0 \% \\
(6 / 25)\end{array}$ & 0.17 & $\begin{array}{l}56.1 \% \\
(1594 / 2843)\end{array}$ \\
\hline Full MRCP (UK) & $\begin{array}{l}40.0 \% \\
(10 / 25)\end{array}$ & $\begin{array}{l}29.4 \% \\
(25 / 85)\end{array}$ & 0.32 & $\begin{array}{l}57.1 \% \\
(4 / 7)\end{array}$ & $\begin{array}{l}24.0 \% \\
(6 / 25)\end{array}$ & 0.17 & NA \\
\hline
\end{tabular}

NA, not available.

MRCP, Membership of the Royal College of Physicians.

adjusted OR=1.67). However, the MRCP Part 2 (Written) pass rate was lower than expected when compared with pass rates in the 2017 UK cohort. This difference may be explained by the timing of the survey which captured data from mentored CMT trainees at the start of their post and who may not have yet attempted the exam. In subpopulation analyses, the pass rates of the MRCP Part 2 (Written) exam was observed to be significantly higher in mentored, IMGs compared with non-mentored IMGs; $71.4 \%(5 / 7)$ vs $24.0 \%(6 / 25), \mathrm{p}<0.05$.

For the MRCP Part 2 (PACES) exam, no significant differences were observed between mentored and non-mentored groups. Non-significant results were also observed in the logistic regression model $(\mathrm{P}=0.23$ and adjusted OR 1.80).

Logistic regression demonstrated that age and the country of primary qualification did not have any significant influence on the effects observed in mentoring for all components of the MRCP (UK) exam.

\section{Higher ARCP pass rates were observed in mentored trainees}

The ARCP review provides a comprehensive assessment of a trainee's progress in the core medical training educational curriculum and personal clinical practice. In our study, 97 trainees (24 mentored, 73 non-mentored) out of 110 had an ARCP within 12 months. The ARCP pass rate (outcome $1 \mathrm{~s}$ ) was observed to be significantly higher in mentored trainees (figure 2A) compared with non-mentored trainees; $95.8 \%(23 / 24)$ vs $69.9 \%(51 / 73), \mathrm{p}<0.05$ $(\mathrm{OR}=9.9,95 \%$ CI 1.5 to 107 and $\mathrm{RR}=1.4,95 \% \mathrm{CI} 1.1$ to $1.7)$.

Mentoring did not significantly decrease the number of SEs, Cls or complaints in CMTs

In our study, although the number of trainee involvement in such events were lower in the mentored group compared with the non-mentored group (figure 2B), $4.0 \%(1 / 25)$ vs $9.4 \%(8 / 85)$ respectively, this was not statistically significant $(\mathrm{p}=0.68)$.

Table 3 Logistic regression table (all figures approximated to two decimal places)

\begin{tabular}{lllcccc}
\hline $\begin{array}{l}\text { Dependent } \\
\text { variable }\end{array}$ & Independent variables & OR & SE & Wald $\chi^{2}$ & P values & 95\% Cl \\
\hline MRCP Part 1 & Age & 0.99 & 0.57 & 0.00 & 0.98 & 0.33 to 3.00 \\
outcome & Mentoring status & 9.56 & 0.67 & 11.28 & $<0.001$ & 2.56 to 35.68 \\
& Primary qualification & 0.47 & 0.54 & 1.89 & 0.17 & 0.16 to 1.37 \\
MRCP Part 2 & Age & 2.01 & 0.52 & 1.81 & 0.18 & 0.73 to 5.53 \\
(Written) & Mentoring status & 1.67 & 0.49 & 1.13 & 0.29 & 0.65 to 4.33 \\
outcome & Primary qualification & 1.08 & 0.51 & 0.02 & 0.88 & 0.40 to 2.90 \\
MRCP Part 2 & Age & 1.67 & 0.52 & 0.97 & 0.32 & 0.60 to 4.65 \\
(PACES) & Mentoring status & 1.80 & 0.48 & 1.47 & 0.23 & 0.70 to 4.65 \\
outcome & Primary qualification & 0.91 & 0.51 & 0.03 & 0.85 & 0.33 to 2.49 \\
\hline
\end{tabular}

MRCP Part 2 (Written) and MRCP Part 2 (PACES) outcomes were omitted when MRCP Part 1 outcome was used as the dependent variable and vice versa.

MRCP, Membership of the Royal College of Physicians; SE, significant events. 
(A)

\section{ARCP Outcomes in Mentored vs Non-Mentored Trainees}

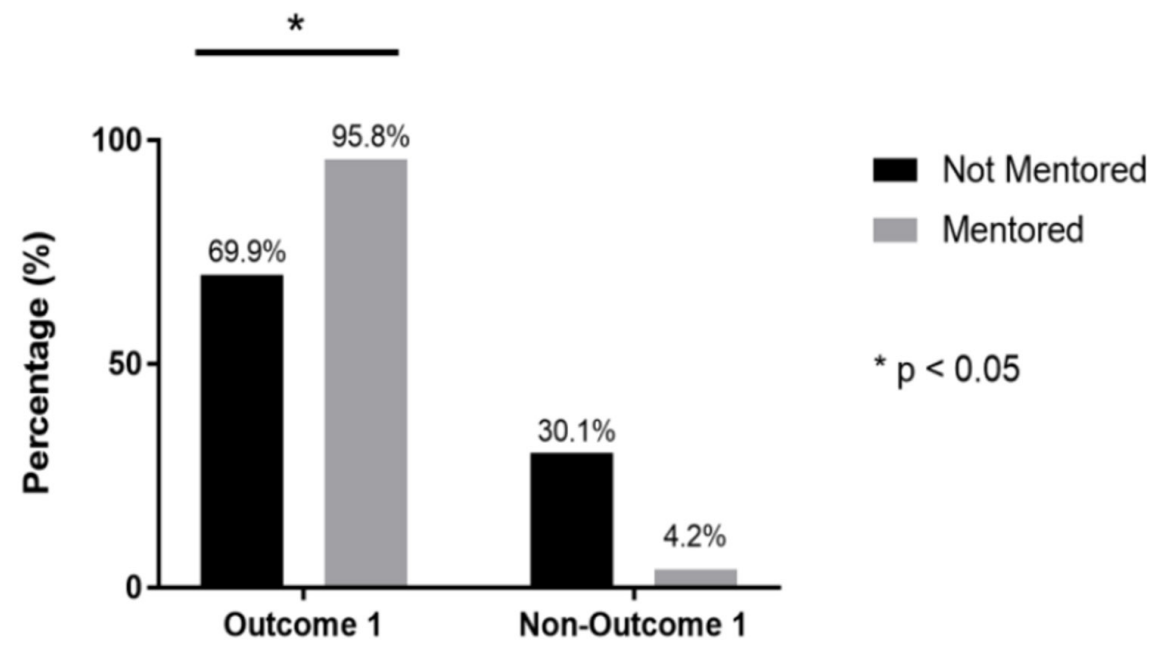

(B)

\section{Trainee Involvement in SEs, Cls or Complaints}

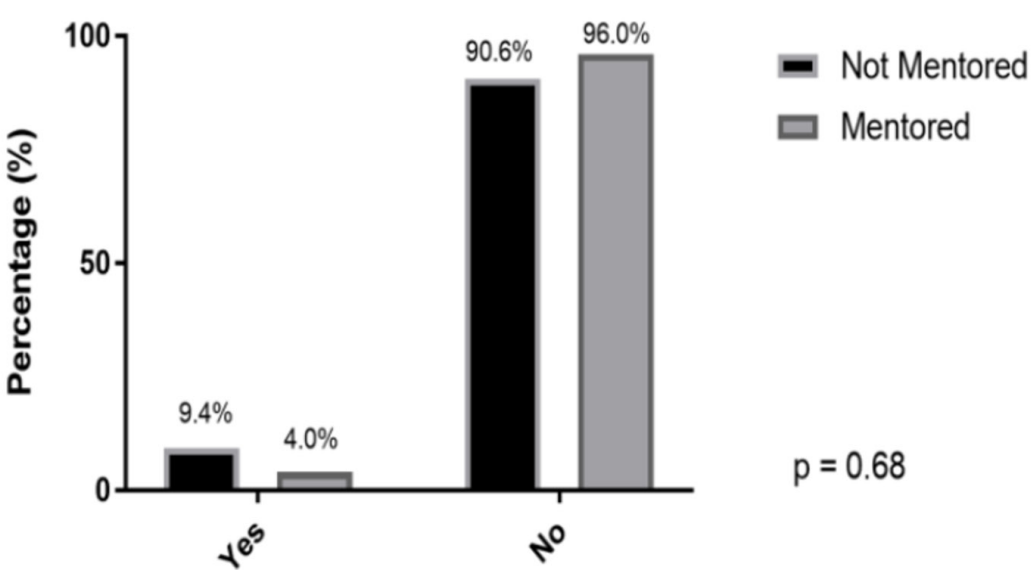

Figure 2 (A) Higher rates of outcome 1 at Annual Review of Competency Progression (ARCP) was observed in mentored trainees, but no statistically significant effect was observed in trainee involvement in significant events (SEs), clinical incidents (Cls) or complaints (B).

Mentoring is associated with increased trainee confidence and better career progression

In total, $69.6 \%(16 / 23)$ of mentored trainees in our study reported that mentoring had improved their confidence (figure 3A) and 95.8\% (23/24) reported mentoring had aided in their career progression in medicine (figure $3 \mathrm{~B}$ ). Exploration of reasons from the mentored trainees who did not find mentoring useful revealed their experience was limited by insufficient time, poor response from mentors and unmet expectations.
The majority of mentored CMTs had a positive experience When asked for their opinion on their mentoring experience, $88.0 \%$ (22/25) of mentored trainees provided positive feedback (figure 3G). A total of $78.2 \%$ (86/110) of all trainees (mentored and non-mentored) agreed with the statement that mentoring should be made available to all CMTs. Only $1.8 \%(2 / 110)$ of responders agreed that mentoring should only be provided to trainees struggling with career progression or clinical work (figure 3D). This suggests mentoring does not confer a negative 
(A)

Did being mentored improve your confidence?

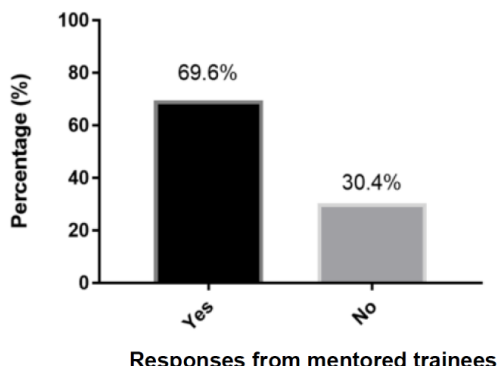

(C)

\section{Comments received from mentored trainees}

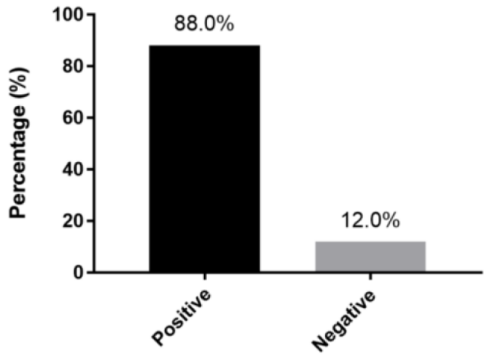

Free-text descriptors used by mentored trainees
(B)

Did mentoring help your career progression?

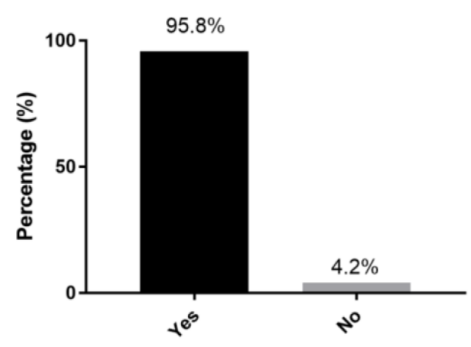

Responses from mentored trainees

(D)

Who should mentoring be made available to?

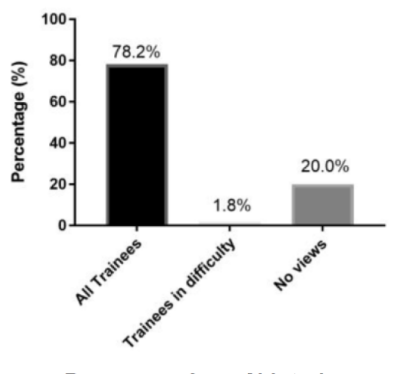

Responses from ALL trainees

Figure 3 The majority of trainees receiving mentorship reported it did help in their (A) confidence and (B) career progression. (C) The majority of mentored trainees provided positive feedback and (D) most trainees in the study were of the opinion that mentoring should be offered to all trainees.

connotation on the mentee by fellow colleagues. Positive and negative descriptors have been summarised in table 4 .

\begin{tabular}{|c|c|c|}
\hline & Descriptors & Phrases \\
\hline \multirow[t]{11}{*}{ Positive } & & \\
\hline & Useful & \multirow{3}{*}{$\begin{array}{l}\text { 'reassuring to know that } \\
\text { someone helpful and supportive } \\
\text { is available' }\end{array}$} \\
\hline & Reassuring & \\
\hline & Enlightening & \\
\hline & $\begin{array}{l}\text { Immensely } \\
\text { positive }\end{array}$ & \multirow{3}{*}{$\begin{array}{l}\text { "helped me streamline my focus } \\
\text { and made me aware of personal } \\
\text { weaknesses" }\end{array}$} \\
\hline & Supportive & \\
\hline & Excellent & \\
\hline & Rewarding & \multirow{2}{*}{$\begin{array}{l}\text { "structured my career goals into } \\
\text { attainable chunks" }\end{array}$} \\
\hline & Helpful & \\
\hline & Transformative & \multirow[t]{2}{*}{ "made me more proactive" } \\
\hline & $\begin{array}{l}\text { Confidence } \\
\text { boosting }\end{array}$ & \\
\hline
\end{tabular}

Negative

$\begin{array}{ll}\text { Basic } & \text { "I did not receive the response } \\ \text { from the mentor I requested" } \\ \text { Not helpful } & \text { 'limited use due to limited time' }\end{array}$

Of the 22 mentored trainees who provided positive feedback, $81.8 \%$ (18/22) had passed MRCP Part 1, 45.5\% (10/22) had passed MRCP Part 2 and 45.5\% (10/22) had completed MRCP PACES. If compared with the 2017 UK cohort, the MRCP Part 1 pass rate is statistically significant $(\mathrm{p}<0.01) ; 86.4 \%(19 / 22)$ of mentored trainees who had a positive experience had received an outcome 1 for their most recent ARCP and none had been involved in any SEs, CIs or complaints. The qualitative data discussed herein reinforces our observations that mentoring did have a significant effect on trainees in practice. Of the three mentored trainees that provided negative feedback, one trainee described mentoring as 'not helpful', one trainee described mentoring as 'basic' and one trainee did not provide any further comments.

\section{Mentee selection of mentors improves compatibility and increases positive experiences}

Analysis of positive feedback from mentored trainees provided valuable insight into the importance of the specialty and gender of mentors. Two examples are provided below.

"I was initially told there was no mentor in my specialty. After a year I was re-contacted because there was a mentor in my specialty. This relationship worked really well. We were able to discuss on Skype and meet in person. It aided my 
confidence and also structured my career goals into attainable chunks."

"This was a transformative experience for me. My mentor was an excellent fit for me (I selected the gender of my mentor only and was then allocated. It was important for me to be mentored by another woman) and provided a space, encouragement, acceptance and deep kindness while asking good questions. This allowed me to grow from a personal perspective and steer my professional life more effectively. I feel better than I have in years and am carving a path that is right for me."

\section{DISCUSSION}

To our knowledge, this study is the first UK-specific study to provide quantitative data showing a positive association between mentoring of junior medical doctors and better training outcomes. Here, the effect of mentoring was assessed against clinically important parameters such as MRCP (UK) pass rates, ARCP pass rates, CIs and SEs, which has not been previously attempted in literature. With regard to the MRCP exams, the strongest association of mentoring with higher pass rates was seen in the MRCP Part 1 exams, where a statistically significant difference was detected when comparing mentored trainees with the non-mentored group. Higher pass rates in the MRCP Part 2 Written exam were also observed in mentored IMGs compared with non-mentored IMG trainees; however, the authors acknowledge that the sample size is small in the aforementioned group and these results should be interpreted with caution.

Interestingly, non-mentored IMGs $(\mathrm{n}=25)$ were observed to have statistically significant lower pass rates in the MRCP Part 2 exams (Written and PACES) compared with mentored IMGs. Also, most mentored IMG trainees began their mentoring relationship before core medical training-two trainees received mentorship as foundation year 2 doctors and two as CMT-equivalent clinical fellows. Further research is needed to see if an earlier introduction of mentoring (eg, during foundation training) in trainees keen on a career in medicine has any effect on training outcomes.

Although mentoring did not have a statistically significant association with trainee involvement in SEs, CIs or complaints, the vast majority of trainees who participated in mentoring found it to be a positive experience which improved confidence and aided in improved career progression. This positive feedback, considered cumulatively with current literature and our observed results, suggests that mentoring may have a genuinely positive effect on postgraduate medical education and development. Similar to current literature, qualitative analysis of feedback from our group of mentored trainees revealed that poor mentor-mentee communication and unmet expectations remain causes of a negative mentormentee experience. This could be addressed in the future by more frequent interval communications with the mentee to detect and address incipient problems.

It has been acknowledged that a facilitative approach is needed in order for a mentor-mentee relationship to be successful $^{316}$; however, this should extend to the mentor and to the mentoring programme that the mentee is engaged in. Although the overall impact of gender specificity of mentors remains a debate in current literature, ${ }^{517}$ there are clearly female mentees who seek female mentors as role models. It is therefore important for any mentoring programme to allow mentees the option to choose their mentors freely as well as recruit and use equal proportions of mentors from both genders.

The benefits of mentoring are not limited to the mentee. Mentoring provides the mentor with personal satisfaction, ${ }^{18}$ an avenue for reflection and the exchange of experiences, ${ }^{3}$ which will in turn enhance one's own professional development. It is important however to stress that mentoring should not be a therapeutic exercise for the senior clinician and that altruistic intentions should be coupled with appropriate training in mentoring, communication and adequate organisational support. Platforms that support mentors or mentees in difficulty should be made easily accessible at any point during the mentoring process.

Mentoring is centred on developing and empowering trainees to realise and achieve their objectives. It should not be restricted to helping trainees in difficulty pass their training, as often in the UK, trainees access mentoring programmes because of compulsory, remedial action or through support offered by higher educational authorities to address exam or domain failures. The majority of CMTs from our survey, together with expert opinions from some RCP tutors, believed that mentoring should be made available to all trainees. It is therefore important to change perspectives among senior medical educators who are opined that mentoring should be encouraged only in trainees who are struggling to progress.

With regard to career progression, our study has also shown that ARCP pass rates were significantly higher in the mentored group, although a contributory reason for this may be that successful completion of the MRCP Part 1 exam is one of the prerequisites for obtaining an outcome 1 (pass) at ARCP for the first year of core medical training. However, the lower ARCP pass rates in the non-mentored group could also have been a result of other domain failures. Therefore, further studies would be needed to identify specifically the impact of mentoring on progression in the other domains.

\section{Limitations of the study and special considerations for future research}

The main limitations of this study arise through the potential for self-selection bias and non-response bias. Trainees within the mentored group have volunteered to be mentored and as such they may be more motivated and highly engaged than those within the non-mentored arm. This could have resulted in self-selection bias. Equally, the low response rate of the survey may have resulted in non-response bias, for example, mentored trainees could have failed their exams and did not respond to the survey causing a skew in the observed results. Both biases would have been minimised if the survey was compulsory. However, there are ethical considerations in making such a survey compulsory as trainees may not give consent to providing non-essential and personal 
information, especially if it involves potentially sensitive issues such as clinical incidents or complaints. We sought to address these issues by keeping all responses anonymous and keeping the survey concise. This would have encouraged more trainees to participate and improved response rates so a better representation of the mentored and non-mentored control groups could be obtained.

A further limitation of the study was the absence of a perfectly matched control group. In theory, the ideal control group for the study would be equally motivated CMTs who had sought mentorship with the RCP but were then matched according to individual attributes and randomised to not receive mentorship. However, this would have been both unethical and against current GMC guidance. We therefore recruited CMTs within the East of England deanery who had not received mentoring as our control group, although we acknowledge this may have introduced selection bias. For added rigour, we have provided the MRCP performance data from 2017 (UK candidates) for comparison and have discussed the reasons for doing so above.

Response rates in unpaid, voluntary research surveys are well known to be poor. The only exception to our knowledge is the GMC National Training Survey because its completion is required before attendance at the ARCP interviews. As a result of the low response rate, sample sizes in some subgroups in the study are small. Therefore, caution is advised when interpreting results in subgroups where small sample sizes may have affected statistical calculations and may not be accurately representative of the entire population.

Lastly, our study design was limited and influenced significantly by the lack of a central platform for data collection and the availability of resources to collate the data. Information on the exam pass rates is held by the MRCP (UK) body and information on the ARCP pass rates, SEs, CIs or complaints is held in confidentiality by a separate body (the Joint Royal Colleges of Physicians Training Board). We found the most cost-effective method of collating data from these two bodies was therefore a survey targeted at trainees who are a common join between the two. Other researchers would therefore need to consider these ethical and logistical challenges in designing future studies.

\section{CONCLUSION}

Our study provides new quantitative data in support of a positive association between mentoring junior doctors and better training outcomes in postgraduate training in general medicine within the UK. Both quantitative and qualitative data from our study supports and reinforces current qualitative literature with similar findings in mentee experiences. Further studies are needed to investigate the causative effects of mentoring on the outcomes of postgraduate medical training.

Acknowledgements The authors would like to thank the National Institute for Health Research (NIHR) Biomedical Research Centre based at Guy's and St Thomas' NHS Foundation Trust, the NIHR Biomedical Research Centre at South London and Maudsley NHS Foundation Trust and King's College London for providing communications, access to literature and statistical support. The authors would also like to thank Ms Daniela Dollinger (Royal College of Physicians) and Ms Sarah Munro (Basildon Hospital) for their assistance.

Contributors J0 and CS designed the study, conducted the literature search, performed the statistical and qualitative analyses, prepared the figures and wrote the manuscript. NM advised on statistical methods, checked the results of the analyses and edited the manuscript. SO and AD gave their expert opinion on medical education in the training of junior doctors and contributed to parts of the manuscript. YA and AS edited the manuscript prior to submission and gave their senior opinion on mentoring in medicine.

Funding This research received no specific grant from any funding agency in the public, commercial or not-for-profit sectors.

Disclaimer The views expressed in this study are those of the author(s) and not necessarily those of the NHS, the NIHR or the Department of Health.

Competing interests $\mathrm{J} 0$ is a voluntary Mentor with the Royal College of Physicians Mentoring scheme described in this manuscript.

Patient consent Not required.

Ethics approval None.

Provenance and peer review Not commissioned; externally peer reviewed.

Data sharing statement No additional data are available, all available data have been disclosed.

Open access This is an open access article distributed in accordance with the Creative Commons Attribution Non Commercial (CC BY-NC 4.0) license, which permits others to distribute, remix, adapt, build upon this work non-commercially, and license their derivative works on different terms, provided the original work is properly cited, appropriate credit is given, any changes made indicated, and the use is non-commercial. See: http://creativecommons.org/licenses/by-nc/4.0/.

\section{REFERENCES}

1. General Medical Council, 2017. Good medical practice: induction and mentoring. http://www.gmc-uk.org/guidance/ethical_guidance/ 11825.asp (accessed 30 Sep 2017).

2. Sambunjak D, Straus SE, Marusić A. Mentoring in academic medicine: a systematic review. JAMA 2006;296:1103-15.

3. Taherian K, Shekarchian M, doctors Mfor. Do its benefits outweigh its disadvantages? Med Teach 2008;30:e95-9.

4. Ackroyd R, Adamson KA. Mentoring for new consultants. J R Coll Physicians Edinb 2015;45:143-7.

5. Straus SE, Johnson MO, Marquez C, et al. Characteristics of successful and failed mentoring relationships: a qualitative study across two academic health centers. Acad Med 2013;88:82-9.

6. Pololi L, Knight S. Mentoring faculty in academic medicine. J Gen Intern Med 2005;20:866-70.

7. Luckhaupt SE, Chin MH, Mangione CM, et al. Mentorship in academic general internal medicine. Results of a survey of mentors. $J$ Gen Intern Med 2005;20:1014-8.

8. Griffiths M, Miller H. E-mentoring: does it have a place in medicine? Postgrad Med J 2005;81:389-90.

9. Schichtel M. Core-competence skills in e-mentoring for medical educators: a conceptual exploration. Med Teach 2010;32:e248-e262.

10. Pillon S, Osmun WE. Mentoring in a digital age. Can Fam Physician 2013;59:442-4

11. NPSA, 2017. Patient safety resources. http://www.nrls.npsa.nhs.uk/ resources/?entryid45=615001 (accessed 30 Sep 2017).

12. Royal College of Physicians (UK), 2017. MRCP(UK) Annual Performance Report (2018). https://www.mrcpuk.org/mrcpukexaminations/results/exam-pass-rates (accessed 9 Feb 2018).

13. Bedrick EJ. A family of confidence intervals for the ratio of two binomial proportions. Biometrics 1987;43:993-7.

14. Baptista J, Pike MC. Exact two-sided confidence limits for the odds ratio in a $2 \times 2$ table. J $R$ Stat Soc C Appl Stat 1977;26:214-20.

15. Rothman KJ. No adjustments are needed for multiple comparisons. Epidemiology 1990;1:43-6.

16. Sackin P, Barnett M, Eastaugh A. Peer-supported learning. British J Gen 1997;47:67-8.

17. Welch JL, Jimenez HL, Walthall J, et al. The women in emergency medicine mentoring program: an innovative approach to mentoring. $J$ Grad Med Educ 2012;4:362-6.

18. Ratnapalan S. Mentoring in medicine. Can Fam Physician 2010;56:198. 